\title{
Effect of Vagus Nerve Stimulation in an Adult Patient with Dravet Syndrome: Contribution to Sudden Unexpected Death in Epilepsy Risk Reduction?
}

\author{
Marianna Spatola ${ }^{a}$ Pierre-Yves Jeannet ${ }^{c}$ Claudio Pollo ${ }^{b}$ Christian Wider ${ }^{a}$ \\ Robyn Labrum $^{\text {d }}$ Andrea O. Rossetti ${ }^{a}$ \\ a Service de Neurologie et ${ }^{b}$ Service de Neurochirurgie, Département de Neurosciences Cliniques, and ${ }^{c}$ Unité de \\ Neuropédiatrie, Département de Pédiatrie, Centre Hospitalier Universitaire Vaudois and University of Lausanne, \\ Lausanne, Switzerland; ' Department of Clinical and Experimental Epilepsy, UCL Institute of Neurology and \\ National Hospital for Neurology and Neurosurgery, UCL, London, UK
}

\section{Key Words}

Vagal nerve stimulator $\cdot \mathrm{SCN1A}$ gene $\cdot$ Treatment $\cdot$ Epilepsy $\cdot$ Neuropsychological impairment $\cdot$ Alertness . Cardiac dysfunction

\begin{abstract}
We report on a patient who developed, from 5 months of age, multiple seizure types, including myoclonic, associated with severe psychomotor delay, leading to the diagnosis of Dravet syndrome. Over the years, he developed refractory epilepsy and was implanted with a vagus nerve stimulator at the age of 19. After 3 months, he experienced a progressive improvement of partial and generalized seizures, with a $>90 \%$ reduction, and better alertness. This meaningful clinical improvement is discussed in the light of the sudden unexpected death in epilepsy risk, which is high in this setting, and seems remarkably diminished in our patient in view of the reduction of generalized convulsions.

Copyright $\odot 2012$ S. Karger AG, Basel
\end{abstract}

\section{Introduction}

Dravet syndrome (DS), or severe myoclonic epilepsy of infancy, manifests with early-onset febrile and nonfebrile generalized convulsive and partial seizures, atypical absence and myoclonus, together with severe psychomotor delay. In almost $80 \%$ of cases, a SCN1A gene mutation is detected, encoding a voltage-gated sodium channel specific to neuronal cells, with a possible role also in cardiac muscle. Treatment is challenging, as anti-epileptic drugs offer only incomplete seizure control, and the risk of sudden unexpected death in epilepsy (SUDEP) is high [1].

Vagus nerve stimulation (VNS) is a recognized supportive therapy for uncontrolled seizures, but so far it has received little attention in DS. Herein, we report a young adult with DS who experienced improved seizure control and cognition following VNS.

\section{Patient Description}

Our patient experienced his first nonfebrile seizure in 1991 at the age of 5 months, and progressively developed almost daily tonic-clonic, myoclonic, and partial complex seizures, as well as

\section{KARGER \\ Fax +4161306 1234 E-Mail karger@karger.ch} www.karger.com
Dr. Andrea O. Rossetti

Service de Neurologie, CHUV-BH07

$\mathrm{CH}-1011$ Lausanne (Switzerland)

E-Mail andrea.rossetti@chuv.ch 
Table 1. Clinical and electrophysiological features before and after implantation of a vagal nerve stimulator

\begin{tabular}{|c|c|c|c|}
\hline & \multirow[t]{2}{*}{ Before VNS (2009) } & \multicolumn{2}{|l|}{ After VNS } \\
\hline & & 1 year of follow-up $(12 / 2010)$ & 2 years of follow-up $(03 / 2012)$ \\
\hline \multicolumn{4}{|l|}{ Seizure frequency } \\
\hline Convulsive generalized & 3-4/month (night/day) & 4/month (nightly only) & 1/3 months (nightly only) \\
\hline Partial or atypical absences & $1-2 /$ month & $1 / 2$ months & none since 9 months \\
\hline Neuropsychological skills & $\begin{array}{l}\text { very poor visual contact } \\
\text { and communication } \\
\text { speech therapy impossible }\end{array}$ & better alertness & $\begin{array}{l}\text { better communication skills } \\
\text { better alertness } \\
\text { able to follow speech therapy }\end{array}$ \\
\hline \multirow[t]{5}{*}{ Medication } & PHT 250 mg daily & PHT 250 mg daily & PHT 200 mg daily \\
\hline & VPA $1,500 \mathrm{mg}$ daily & VPA $1,500 \mathrm{mg}$ daily & VPA $1,300 \mathrm{mg}$ daily \\
\hline & LEV 1,000 mg daily & LEV 1,000 mg daily & LEV 1,000 mg daily \\
\hline & CLBZ 30 mg daily & CLBZ 30 mg daily & CLBZ 30 mg daily \\
\hline & & & RTG 400 mg daily \\
\hline \multirow[t]{4}{*}{ VNS parameters } & - & $1.5 \mathrm{~mA}$ & $2.25 \mathrm{~mA}$ \\
\hline & & $500 \mu \mathrm{s}$ & $500 \mu s$ \\
\hline & & $30 \mathrm{~Hz}$ & $30 \mathrm{~Hz}$ \\
\hline & & $30 \mathrm{~s}$ on $/ 5 \mathrm{~min}$ off & $30 \mathrm{~s}$ on $/ 3 \mathrm{~min}$ off \\
\hline
\end{tabular}

$\mathrm{PTH}=$ Phenytoin; VPA = valproic acid $\mathrm{LEV}=$ levetiracetam; CLBZ = clobazam; $\mathrm{RTG}=$ retigabine.

several episodes of status epilepticus, leading to the clinical diagnosis of DS. Different anti-epileptic treatments (i.e. phenobarbital, phenytoin, carbamazepine, valproate, lamotrigine, gabapentine, vigabatrin, levetiracetam, benzodiazepines), showed only incomplete efficacy. DNA sequencing of the SCN1A gene revealed a heterozygous c.5536_5539delAAAC;p.Lys1846Serfs mutation, a 4 -bp deletion resulting in a truncated protein, previously reported in DS [2].

At the age of 19, in November 2009, the patient was implanted with a vagal nerve stimulator on his left side (Cyberonics, Houston, Tex., USA), with stimulation parameters progressively increased, as shown in table 1 . Three months later, he experienced increasing improvement in seizure control and achieved, at last follow-up visit (28 months after implantation), better alertness/ cognition and an overall seizure frequency reduction of $>90 \%$ (table 1), corresponding to a class I-A (80-100\% reduction in seizure frequency) in the VNS-specific McHugh's scale [3]. Moreover, the magnet was reported to shorten seizures and fasten recovery.

\section{Discussion}

Our report illustrates the efficacy of VNS in a young adult with pharmacoresistant epilepsy caused by DS, resulting in improved seizure control and neuropsychological/social skills, both contributing to a better quality of life. Although the combination of VNS and the pharmacological therapy likely contributed to the final result, the retigabine daily dose appears low (especially with a concomitant enzyme inducer such as phenytoin), supporting the chronic effect of VNS.

These results are consistent with previous observations: similarly to a few, a recent retrospective study on DS [4] reported a 30-60\% reduction of epileptic events with positive effects on cognition and alertness. In contrast to that study, our patient also showed some benefit from the magnet activation.

Most importantly, since the treatment greatly reduced generalized seizures, VNS may influence the risk of SUDEP, which is known to be associated with poor seizure control, male gender, young age at epilepsy onset and polytherapy [5]. SUDEP remains an important cause of mortality in DS, accounting for $15-60 \%$ of deaths [1], and seems to have a higher incidence in DS than in other epileptic encephalopathies, suggesting an additional risk specific to this syndrome. SUDEP is thought to be due to cardio-respiratory events linked to prolonged seizures involving cerebral areas concerned in autonomic control (temporal lobe or insula). In DS, autonomic dysfunction has been observed, with reduced heart rate variability and predominant sympathetic tone [6]. Interestingly, a genetic base of this observation has been proposed, since the SCN1A gene product seems to be involved in normal cardiac functioning in animals [7]. Moreover, in humans, 
the relationship between sodium channelopathies and potentially fatal cardiac arrythmias has been well documented [8]. These observations could suggest a common genetic background for both neuronal and cardiac impairment in DS.

Since VNS stimulates autonomous fibers, the risk of vagally-mediated heart dysfunction has been questioned. Transitory cardiac arrhythmias are occasionally described during implantation, and 2 patients showed postimplantation periodic bradycardia/asystolia, both revers- ible after VNS discontinuation [9]. To date, VNS does not seem to increase the SUDEP risk in patients with epilepsy, with a relatively large cohort showing a sudden-death rate similar to the general epileptic population [10].

In conclusion, VNS may influence mortality by acting both on cerebral and autonomous dysfunction, which are possibly linked to neuronal and cardiac effect of SCN1A gene. Further studies are fundamental to better investigate the relationship between VNS and SUDEP risk in this specific population.

\section{References}

1 Genton P, Velizarova R, Dravet C: Dravet syndrome: the long-term outcome. Epilepsia 2011;52(suppl 2):44-49.

2 Claes L, Del-Favero J, Ceulemans B, Lagae L, Van Broeckhoven C, De Jonghe P: De novo mutations in the sodium-channel gene SCN1A cause severe myoclonic epilepsy of infancy. Am J Hum Genet 2001;68:13271332.

3 McHugh JC, Singh HW, Phillips J, Murphy K, Doherty CP, Delanty N: Outcome measurement after vagal nerve stimulation therapy: proposal of a new classification. Epilepsia 2007;48:375-378.

$\checkmark 4$ Zamponi N, Passamonti C, Cappanera S, Petrelli C: Clinical course of young patients with Dravet syndrome after vagal nerve stimulation. Eur J Paediatr Neurol 2011;15: 8-14.
5 Hesdorffer DC, Tomson T, Benn E, Sander JW, Nilsson L, Langan Y, Walczak TS, Beghi E, Brodie MJ, Hauser A: Combined analysis of risk factors for SUDEP. Epilepsia 2011;52: 1150-1159.

6 Delogu AB, Spinelli A, Battaglia D, Dravet C, De Nisco A, Saracino A, Romagnoli C, Lanza GA, Crea F: Electrical and autonomic cardiac function in patients with Dravet syndrome. Epilepsia 2011;52(suppl 2):55-58.
7 Maier SK, Westenbroek RE, Yamanushi TT, Dobrzynski H, Boyett MR, Catterall WA, Scheuer T: An unexpected requirement for brain-type sodium channels for control of heart rate in the mouse sinoatrial node. Proc Natl Acad Sci USA 2003;100:3507-3512.

$\checkmark 8$ Amin AS, Asghari-Roodsari A, Tan HL: Cardiac sodium channelopathies. Pflügers Arch 2010;460:223-237.

9 Iriarte J, Urrestarazu E, Alegre M, Macías A, Gómez A, Amaro P, Artieda J, Viteri C: Lateonset periodic asystolia during vagus nerve stimulation. Epilepsia 2009;50:928-932.

$>10$ Annegers JF, Coan SP, Hauser WA, Leestma $\mathrm{J}$ : Epilepsy, vagal nerve stimulation by the NCP system, all-cause mortality, and sudden, unexpected, unexplained death. Epilepsia 2000;41:549-553. 